\title{
Differentiated (Simplex) Penile Intraepithelial Neoplasia
}

\author{
National Cancer Institute
}

\section{Source}

National Cancer Institute. Differentiated (Simplex) Penile Intraepithelial Neoplasia. NCI

Thesaurus. Code C162539.

Intraepithelial neoplasia of the penis usually presenting as a solitary white or pink macule or plaque that may be slightly elevated. A background of long-standing lichen sclerosus is often present. It is characterized by a thickened epithelium, subtle abnormal cellular maturation, and atypical basal layer cells. Parakeratosis is common. (WHO 2016) 